\title{
Exploring Mind Maps for Assessment in an Introductory Chemical Engineer- ing Course
}

\section{Prof. Joshua A Enszer, University of Delaware}

Prof. Joshua Enszer is an assistant professor in Chemical and Biomolecular Engineering at the University of Delaware. He has taught core and elective courses across the curriculum, from introduction to engineering science and material and energy balances to process control, capstone design, and mathematical modeling of chemical and environmental systems. His research interests include technology and learning in various incarnations: electronic portfolios as a means for assessment and professional development, implementation of computational tools across the chemical engineering curriculum, and game-based learning. 


\title{
Exploring Mind Maps for Assessment in an Introductory Chemical Engineering Course
}

\begin{abstract}
Mind maps are a study tool for students to visualize and organization in a way that emphasizes the way that concepts are connected to one another. Their use has been documented in several technical fields, including medicine, industrial engineering, and environmental engineering. Many publications on the use of mind maps or concept maps include one or more ideas on how to assess the quality of these diagrams.

In this work in progress, we summarize different ways that have already been proposed and implemented in the literature to evaluate mind maps. Some rubrics view a map holistically, while others attempt to deconstruct maps into component pieces, like number of topics or number of connections, for scoring. We describe our experiences using some of these approaches in evaluating our own use of mind maps in the classroom.

We have collected two years' worth of mind maps from the University of Delaware's Introduction to Chemical Engineering course as part of an end-of-semester exercise that is presented to students as a final exam preparation activity. We seek to address two questions using this activity: (1) Is there any relationship between the quality of mind maps and student performance in the course, and (2) Is there any significant change between the 2016 and 2017 student responses that may have resulted from changes made to the course between these years? Indirectly, we seek to determine whether mind maps would be a useful measure for direct assessment to track continuous improvement initiatives related to this course. We also seek to determine whether one established strategy for assessing mind maps is more amenable to addressing these questions than others.
\end{abstract}

\section{Introduction}

Mind maps are graphical, two-dimensional displays of concepts or ideas and their relationships. Each concept or idea is a node in a graph, and nodes that contain related concepts or ideas are connected with edges. Mind maps are a simplification to concept maps, which strictly require each edge to be labeled with a description of the relationship between two connected nodes. Mind maps have been used as a study tool for decades, and in recent years have been explored in a number of disciplines, to explore information retention over time [1], or to seek connections between the use of mind maps and critical thinking [2]. Some have proposed ways to assess maps [1,3] or reported on use of existing rubrics [4].

Mind maps and concept maps can be evaluated in different ways, though generally two categories of evaluation seem to be implemented in the literature: a "holistic" view that assesses the overall map in terms of its content and structure, or a "hierarchical" evaluation based on counting up elements of the structure of the map. Holistic rubrics assign scores to desired attributes of a map, with subscores generally on a 3- or 4-point scale, while hierarchical rubrics award points for the number of features, resulting in a score that technically has no upper limit. One example of each type of rubric follows, though several variations on each are available. 
Besterfield et al. explored the use of concept maps to assess "knowledge integration" in industrial engineering at the University of Pittsburgh [1]. In their study, after a brief overview of mind maps and their creation, students were asked to create a mind map of the field of industrial engineering in their second year of study and then again in their fourth year. Working with experts in the field, they developed a holistic rubric that scored students on comprehensiveness, organization, and correctness. A brief summary of the rubric is shown in Table 1.

Table 1: Concept Map Scoring Rubric from Besterfield et al.

\begin{tabular}{|l|l|l|l|}
\hline & 1 & 2 & 3 \\
\hline Comprehensiveness & $\begin{array}{l}\text { Map is limited in } \\
\text { breadth and barely } \\
\text { covers some qualities } \\
\text { of the subject. }\end{array}$ & $\begin{array}{l}\text { Map is limited in } \\
\text { some areas or } \\
\text { suggests a narrow } \\
\text { understanding of } \\
\text { subject. }\end{array}$ & $\begin{array}{l}\text { Map lacks no more } \\
\text { than one "extension } \\
\text { area" related to } \\
\text { subject. }\end{array}$ \\
\hline Organization & $\begin{array}{l}\text { Concepts are not well } \\
\text { connected with few } \\
\text { or no non-linear } \\
\text { connections. }\end{array}$ & $\begin{array}{l}\text { Some integration of } \\
\text { branches, possibly } \\
\text { with a few loops. }\end{array}$ & $\begin{array}{l}\text { Well integrated } \\
\text { connections with } \\
\text { sophisticated branch } \\
\text { structure and loops. }\end{array}$ \\
\hline Correctness & $\begin{array}{l}\text { Naïve and contains } \\
\text { misconceptions or } \\
\text { inaccuracies. }\end{array}$ & $\begin{array}{l}\text { Few inaccuracies in } \\
\text { concepts or links. }\end{array}$ & $\begin{array}{l}\text { Reflects accurate } \\
\text { understanding of } \\
\text { subject. }\end{array}$ \\
\hline
\end{tabular}

Novak and Gowin [5] propose a more algorithmic hierarchical evaluation based on a mind map's structure. They define a hierarchy with in the map, with the "key concept" at the top (or in the center) of the map. General concepts related to the key concept are nodes connected to the key concept, and these general concepts are the first "level" of depth of the map. Additional levels of less general concepts can be added, and so on, down to an end-level of "examples," or specific objectives that are instances of the concept listed in the previous level. Any connections between concepts that link different levels are called "cross links." One example rubric used to score mind maps hierarchically is shown in Figure 1.

Links (if valid): 1 pt each

Levels (if valid): 5 pts each

Cross links (if valid and significant enough): 10 pts each

Examples (if valid): 1 pt each

Total: 5 links +2 levels +1 cross link $=25$ pts

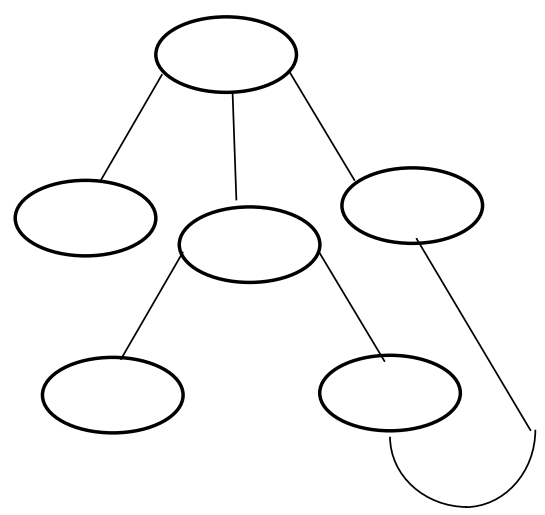

Figure 1. Hierarchical scoring model for mind maps 


\section{Methods}

The University of Delaware is a medium-sized, mid-Atlantic, public institution whose undergraduate population is $93 \%$ full-time and $7 \%$ part-time. The overall population is $58 \%$ female and $42 \%$ male, with about $22 \%$ underrepresented groups (non-White, non-Asian students). In chemical engineering, the undergraduate population is $29 \%$ female with about $16 \%$ underrepresented groups.

Our first-year students take Introduction to Chemical Engineering in the spring as their first required course in the major. While the only strict co-requisite is Calculus II, the majority of the students take second-semester introductory chemistry simultaneously.

In the final week of Introduction to Chemical Engineering, as part of the course wrap-up and preparation for final exams, students are given their last set of active learning instructions. One of the worksheets is a short prompt about the creation of a mind map:

On this page, construct a mind map of this discipline. Connect related items with lines or arrows. Toward the edges of the page, include items from previous and future engineering courses and real-world applications. If necessary, for clarity, label the lines that connect related items. You may rotate this page, or use the back instead, if needed.

Less than five minutes was spent as lecture explaining what a mind map was and showing brief examples. Then students had fifteen minutes to work individually on generating their maps using pencil and paper. They were told that their maps would be collected but not evaluated for a grade. Electronic copies of the maps were made, and maps were offered back to the students in the last day of lecture for the semester.

As a preliminary start to this work in progress, ten maps chosen at random from the 2016 and 2017 semesters were evaluated in random order according to the holistic rubric from Besterfield et al. It is also planned to use a more hierarchical rubric to reevaluate the rubrics. Ultimately this will be done for each of the approximately 90 mind maps from both the 2016 and 2017 iterations. Scores on the maps will be compared to address the two underlying questions: (1) Does performance on this mind map exercise have a relationship to course grade? (2) Is there a difference between the 2016 and 2017 cohorts?

\section{Results and Discussion}

As this is an introductory chemical engineering course, scores on the holistic rubric were low on average (subscore means of 1.45 for the Comprehensive rating, 1.45 for the Organization rating, and 1.35 for the Correctness rating, resulting in an average score of 4.25). The average total score among the 2016 cohort was a 4.8, with the average score among the 2017 cohort a 3.7. With small samples, there is no statistically significant difference between the cohorts.

Both the raw total score and the subscores on the holistic mind map rubric were compared against course grade (converted to Grade Points, so $A=4, B=3, C=2, D=1$ ) and subject to a linear or multiple linear correlation. The relationship between total score and course GPA are 
somewhat correlated $(\alpha<0.05)$. The individual and predicted results are shown in Figure 2 . Notably for this sample, the highest mind map rubric score for students earning D's in the class was 4 points; however, there were also several students with higher grades that also scored 3 or 4 points on the rubric. The predicted course grade increases with increasing rubric score with a slope of $95 \%$ confidence interval $0.52 \pm 0.46$. More significant discussion will be added after a larger number of mind maps are assessed.

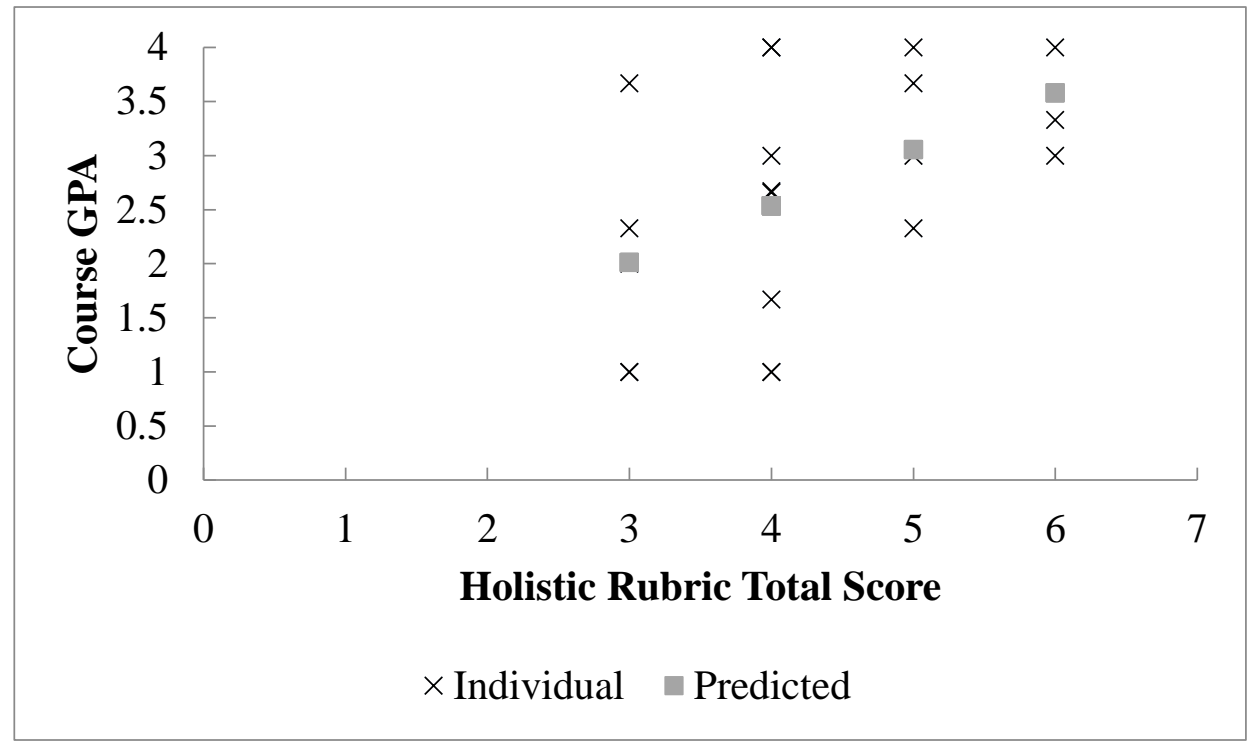

Figure 2: Course GPA as predicted by holistic rubric score

When looking at the subscores of the holistic rubric, it appears that only the Comprehensiveness subscore has a correlation with course GPA. Similar to the other regression comparison to individual results, while students with a low subscore earned grades from A to D, no one with a D grade had a moderate subscore.

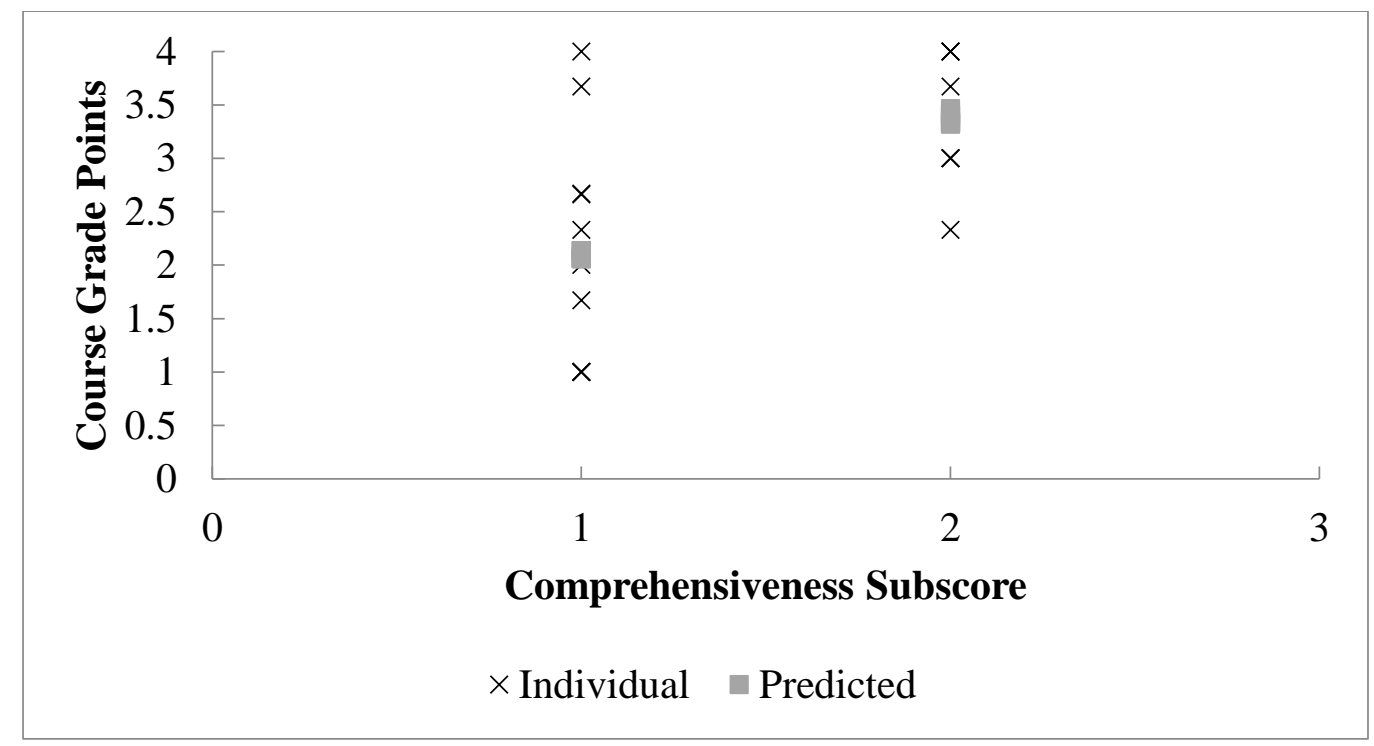

Figure 3: Course GPA as predicted by Comprehensiveness subscore on holistic rubric 


\section{Conclusion and Next Steps}

As of now, the rubrics assessed indicate a slight correlation between student ability to generate a comprehensive picture of their discipline and their performance in the Introduction to Chemical Engineering course. Once the entire set of rubrics has been evaluated using the example holistic and hierarchical rubrics, correlations between (sub)scores and course performance will be explored in further detail. Mind maps will also be implemented again in the spring 2018 semester, though these data will only be available for analysis and discussion in time for the conference.

\section{References}

[1] M. Besterfield-Sacre, J. Gerchak, M. Lyons, L. J. Shuman, and H. Wolfe, "Scoring concept maps: an integrated rubric for assessing engineering education." J. Engr. Educ., vol. 38, pp. 105115, Apr. 2004.

[2] A. V. D'Antoni, G. P. Zipp, V. G. Olson, and T. F. Cahill, "Does the min map learning strategy facilitate information retrieval and critical thinking in medical students?" BMC Med. Educ., vol. 10, no. 61.

[3] E. Evrekli, D. Inel, and A. Balim, "Development of a scoring system to assess mind maps." Procd. Soc. Behv., vol. 2, pp. 2330-2334, 2010.

[4] R. O'Connor, "The use of mind maps as an assessment tool," in International Conference on Engaging Pedagogy 2011, NCI, Dublin, Ireland. December 16, 2011.

[5] J. D. Novak and D. B. Gowin, Learning how to learn. New York: Cambridge University Press, 1984. 